\title{
Site-specific Probabilistic Seismic Hazard Map of Himachal Pradesh, India. Part I. Site-specific Ground Motion Relations
}

\author{
Prabhu MUTHUGANEISAN and S.T.G. RAGHUKANTH \\ Department of Civil Engineering, Indian Institute of Technology Madras, \\ Chennai, India; e-mail: raghukanth@iitm.ac.in
}

\begin{abstract}
This article presents four regional site-specific ground motion relations developed for the state of Himachal Pradesh in northwest Himalaya, situated in a seismically active region. These relations are developed from synthetic free surface ground motion databases obtained from a calibrated stochastic seismological model considering the characteristic properties of this specific region. The adopted methodology incorporates the site effects characterised through active MASW tests conducted in 22 important cities. The estimated ground motion levels from the developed relations are found to be in reasonable agreement with the recorded data.
\end{abstract}

Key words: PSHA, GMPE, seismic hazard, site coefficients, Himalaya.

\section{INTRODUCTION}

Himachal Pradesh (HP), the study region, is a northern state in India situated in the western part of the seismically active Himalayan region. This region has experienced several major earthquakes in the past, namely, the Kangra earthquake $(M w 7.8,1905)$ with its epicenter in the Kangra region, which resulted in extensive damages to infrastructure and human life. The seismic zone map of India presented in IS:1893 (2002) has assigned this region as

Ownership: Institute of Geophysics, Polish Academy of Sciences;

(C) 2016 Muthuganeisan and Raghukanth. This is an open access article distributed under the Creative Commons Attribution-NonCommercial-NoDerivs license,

http://creativecommons.org/licenses/by-nc-nd/3.0/. 
Zone IV (severe) and V (very severe) with damage intensity of VIII and IX, respectively. Despite the natural hazard posed to this region, the demand posed by tourism and topology has made the land a prime commodity leading to congested development and bunching of population in the major cities and towns. Additionally, the rapid population increase has resulted in several unplanned urban development and unscientific road-cuts in this hilly region. In addition, the state has been promoting several important projects such as hydroelectric power projects, tunnels, roads, etc. Without consideration of the appropriate seismic hazard of this region, these construction designs face the risk of being vulnerable during a probable seismic event larger than the considered design basis earthquake, thereby risking the human life and the investments.

An important aspect of hazard estimation is the availability of a reliable ground motion relation. But, the lack of reliable ground motion database for Himalayan region, which is complete for all magnitude, distance, and frequency ranges, is a constraint on the development of such regional ground motion relations. The NDMA (2011) report circumvented this issue by developing ground motion relations specific to the Indian subcontinent, based on synthetic ground motion database generated by considering the regional geology and seismic source characteristics. However, these relations were presented for class A sites, which are less common in the young mountains of Himachal Pradesh. This became evident from the Multi-channel analysis of Surface Waves (MASW) tests conducted at 73 locations spread across Himachal Pradesh. The results of the MASW tests, which are presented in the Section 2 of this article, indicates that none of the test sites were of class A type, instead most of these sites are of class $C$ and $D$ with a couple of class B sites. This necessitates the need to extend the applicability of the NDMA (2011) ground motion relations to other prevailing site conditions in Himachal Pradesh while incorporating the regional seismological characteristics.

Hence, this article presents four site- and region-specific ground motion relations developed for Himachal Pradesh incorporating the regional seismic characteristics and local site effects. The predictions of these proposed ground motion relations are validated with recorded data from the study region. In the companion paper (Muthuganeisan and Raghukanth 2016), the developed ground motion relations have been used to estimate the sitespecific hazard of the state of Himachal Pradesh within a probabilistic framework.

\section{SITE CHARACTERIZATION USING MASW TEST}

The salient feature of this study is incorporating the local site effects prevailing in HP while estimating the seismic hazard as it is well known that the site conditions significantly alter the ground motion characteristics, resulting 
in the amplification of the ground motion in certain frequency ranges. The geographical setting of the HP, aided by the extreme variation in the altitude and climatic conditions, clearly indicates that there is a large spatial variation in the site characteristics across the region. Therefore, the hazard maps produced by NDMA (2011) which are valid for A type sites or hard rock level cannot be used directly. In this study, the dynamic properties of the soil strata has been characterized by developing shear wave velocity profiles of the top soil for a depth of $30 \mathrm{~m}$, which is a good indicator of the elastic soil response (IBC 2009).

In this study, the Multi-channel Analysis of Surface Waves (MASW) technique (Park et al. 1999), which is an efficient non-destructive technique, was chosen for estimating the shear wave velocity profile up to $30 \mathrm{~m}$ of the soil strata. The active source consist of a sledge hammer, weighing $8 \mathrm{~kg}$, with an automatic trigger struck against a metal plate placed firmly on the ground surface. The striking action generates Rayleigh type surface waves, which are recorded by an array of receivers, called geophones, placed at known distances. The variation of the shear wave velocity across the depth can be found by analyzing these waves in the frequency wave number domain.

Figure 1a shows a schematic view of the test setup and shot location. The experimental setup consists of a 24-channel Geode of ultra-light exploration seismograph class from Geometrics with the following properties: 24-bit, ultra-high resolution $20 \mathrm{kHz}$ bandwidth ( 8 to $0.02 \mathrm{~ms}$ sampling), low distortion $(0.0005 \%)$, low noise $(0.2 \mu \mathrm{V})$, stacking accuracy (1/32 of sample interval). The tests were performed with a linear spread of $4.5 \mathrm{~Hz}$ frequency geophones with fixtures made for both soft and hard surface. The spread length of the geophones varied from 16 to $72 \mathrm{~m}$ with the spacing interval ranging from 1 to $5 \mathrm{~m}$. Sampling interval of $0.125 \mathrm{~ms}$ and a record length of $5 \mathrm{~s}$ was found to adequately capture the waveforms. Multiple shot gathers were stacked to improve the signal to noise ratio of the data. Also, the geophones located far from the source were set to highest gain to improve the strength of the signal. The geophones are placed in equally spaced linear array and can detect the vertical component of the ground motion caused due to the source. The data from all the geophones are collected by the Geode and are sent as digital records to a computer. A sample waveform of the acquired data with the shot location at $-2 \mathrm{~m}$ away from the first geophone is shown in Fig. 1b. Since this waveform corresponds to the shot position 1, it can be seen that the first geophone has received the first arrival and the travel time to reach the other geophones can be observed from the arrival of the first breaks of other geophone readings. The signals are then filtered to remove any ambient noise. These signals are then transformed into the frequency- 
(a)

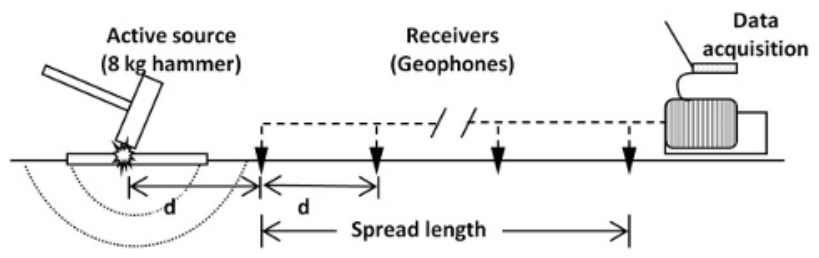

(b)

(c)

(d)
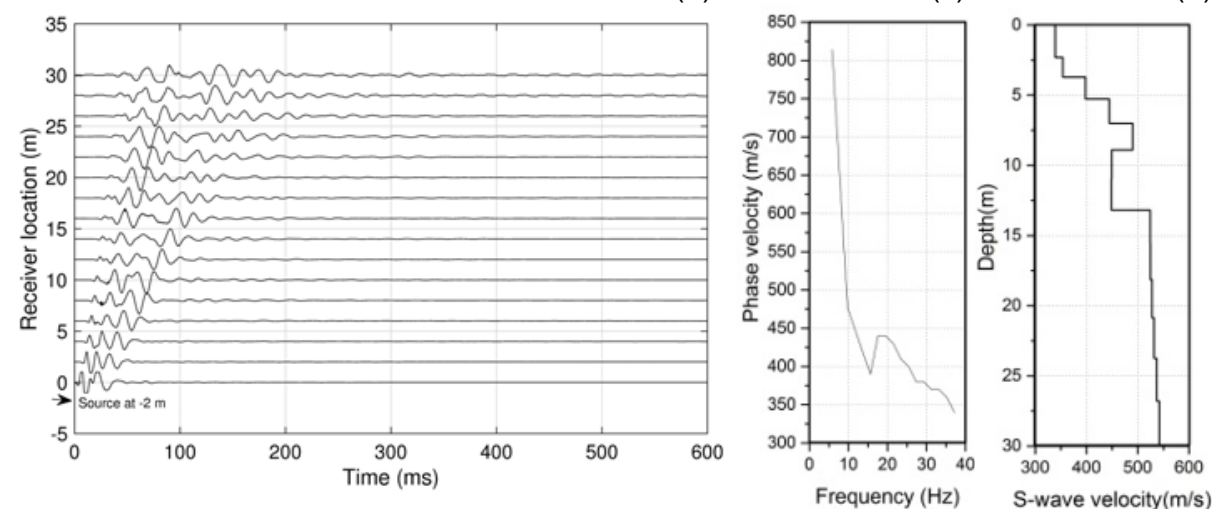

Fig. 1: (a) Schematic view of MASW test, (b) typical waveform of the acquired data. Shot gather at Kullu (KL-4) test site when the source is at $-2 \mathrm{~m}$ away from the first receiver, (c) the corresponding dispersion curve, (d) the corresponding shear wave velocity profile.

(a)

(b)
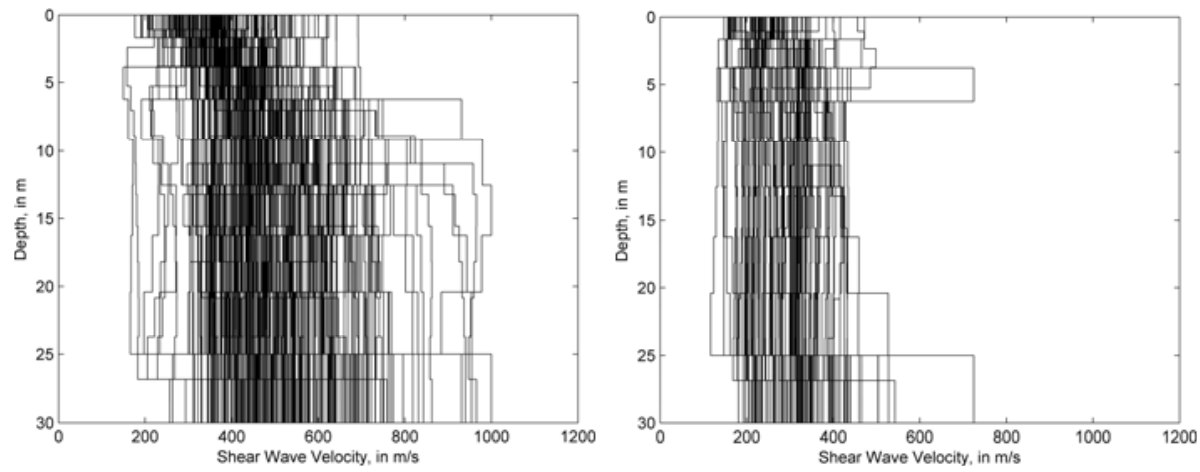

Fig. 2. $V s_{30}$ profile of all the: (a) 50 class $\mathrm{C}$ sites, and (b) 21 class D sites.

phase velocity domain to obtain the dispersion curve, as shown in Fig. 1c, which would reveal the dominant phase velocities versus frequency and is an indicator of the variation of the body wave velocities with the soil depth. Using inversion method, the variation of the shear wave velocity across the soil 
Table 1

Site averaged $V_{S_{30}}$ values and IBC (2009) site classification of all the test sites in the 22 cities measured by MASW tests

\begin{tabular}{|c|c|c|c|c|}
\hline Site id & City name & Location & $\begin{array}{c}\text { Average } V s_{30} \\
{[\mathrm{~m} / \mathrm{s}]}\end{array}$ & Soil type \\
\hline $\mathrm{B} 1$ & & $31.34^{\circ} \mathrm{N} 76.76^{\circ} \mathrm{E}$ & 483 & $\mathrm{C}$ \\
\hline B2 & & $31.32^{\circ} \mathrm{N} 76.76^{\circ} \mathrm{E}$ & 405 & $\mathrm{C}$ \\
\hline B3 & Bilaspur* & $31.33^{\circ} \mathrm{N} 76.77^{\circ} \mathrm{E}$ & 659 & $\mathrm{C}$ \\
\hline B4 & & $31.34^{\circ} \mathrm{N} 76.76^{\circ} \mathrm{E}$ & 626 & $\mathrm{C}$ \\
\hline B5 & & $31.34^{\circ} \mathrm{N} 76.76^{\circ} \mathrm{E}$ & 391 & $\mathrm{C}$ \\
\hline $\mathrm{C} 1$ & & $32.55^{\circ} \mathrm{N} 76.13^{\circ} \mathrm{E}$ & 542 & $\mathrm{C}$ \\
\hline $\mathrm{C} 2$ & & $32.54^{\circ} \mathrm{N} 76.13^{\circ} \mathrm{E}$ & 326 & $\mathrm{D}$ \\
\hline $\mathrm{C} 3$ & Chamba* & $32.55^{\circ} \mathrm{N} 76.13^{\circ} \mathrm{E}$ & 343 & $\mathrm{D}$ \\
\hline $\mathrm{C} 4$ & & $32.56^{\circ} \mathrm{N} 76.12^{\circ} \mathrm{E}$ & 600 & $\mathrm{C}$ \\
\hline $\mathrm{C} 5$ & & $32.56^{\circ} \mathrm{N} 76.13^{\circ} \mathrm{E}$ & 291 & $\mathrm{D}$ \\
\hline D1 & Dankar & $32.09^{\circ} \mathrm{N} 78.22^{\circ} \mathrm{E}$ & 413 & $\mathrm{C}$ \\
\hline DH1 & & $32.20^{\circ} \mathrm{N} 76.32^{\circ} \mathrm{E}$ & 473 & $\mathrm{C}$ \\
\hline $\mathrm{DH} 2$ & & $32.20^{\circ} \mathrm{N} 76.34^{\circ} \mathrm{E}$ & 460 & $\mathrm{C}$ \\
\hline DH3 & Dhramshala* & $32.21^{\circ} \mathrm{N} 76.32^{\circ} \mathrm{E}$ & 437 & $\mathrm{C}$ \\
\hline DH4 & & $32.22^{\circ} \mathrm{N} 76.33^{\circ} \mathrm{E}$ & 597 & $\mathrm{C}$ \\
\hline DH5 & & $32.21^{\circ} \mathrm{N} 76.34^{\circ} \mathrm{E}$ & 432 & $\mathrm{C}$ \\
\hline H1 & & $31.69^{\circ} \mathrm{N} 76.52^{\circ} \mathrm{E}$ & 449 & $\mathrm{C}$ \\
\hline $\mathrm{H} 2$ & & $31.71^{\circ} \mathrm{N} 76.53^{\circ} \mathrm{E}$ & 637 & $\mathrm{C}$ \\
\hline H3 & Hamirpur* & $31.67^{\circ} \mathrm{N} 76.53^{\circ} \mathrm{E}$ & 502 & $\mathrm{C}$ \\
\hline $\mathrm{H} 4$ & & $31.69^{\circ} \mathrm{N} 76.51^{\circ} \mathrm{E}$ & 227 & $\mathrm{D}$ \\
\hline H5 & & $31.68^{\circ} \mathrm{N} 76.54^{\circ} \mathrm{E}$ & 561 & $\mathrm{C}$ \\
\hline KP1 & Kalpa & $31.54^{\circ} \mathrm{N} 78.26^{\circ} \mathrm{E}$ & 394 & $\mathrm{C}$ \\
\hline KG1 & Kangra fort & $32.09^{\circ} \mathrm{N} 76.26^{\circ} \mathrm{E}$ & 853 & $\mathrm{~B}$ \\
\hline KZ1 & Kaza & $32.23^{\circ} \mathrm{N} 78.07^{\circ} \mathrm{E}$ & 699 & $\mathrm{C}$ \\
\hline KE1 & Kee & $32.30^{\circ} \mathrm{N} 78.01^{\circ} \mathrm{E}$ & 691 & $\mathrm{C}$ \\
\hline $\begin{array}{l}\text { KY1 } \\
\text { KY2 }\end{array}$ & Keylong* & $\begin{array}{l}32.57^{\circ} \mathrm{N} 77.03^{\circ} \mathrm{E} \\
32.57^{\circ} \mathrm{N} 77.04^{\circ} \mathrm{E}\end{array}$ & $\begin{array}{l}493 \\
300\end{array}$ & $\begin{array}{l}\mathrm{C} \\
\mathrm{D}\end{array}$ \\
\hline KL1 & & $31.94^{\circ} \mathrm{N} 77.11^{\circ} \mathrm{E}$ & 407 & $\mathrm{C}$ \\
\hline KL2 & & $31.96^{\circ} \mathrm{N} 77.11^{\circ} \mathrm{E}$ & 521 & $\mathrm{C}$ \\
\hline KL3 & Kullu* & $31.96^{\circ} \mathrm{N} 77.11^{\circ} \mathrm{E}$ & 467 & $\mathrm{C}$ \\
\hline KL4 & & $31.96^{\circ} \mathrm{N} 77.11^{\circ} \mathrm{E}$ & 495 & $\mathrm{C}$ \\
\hline KL5 & & $31.96^{\circ} \mathrm{N} 77.12^{\circ} \mathrm{E}$ & 392 & $\mathrm{C}$ \\
\hline ML1 & & $32.23^{\circ} \mathrm{N} 77.19^{\circ} \mathrm{E}$ & 416 & $\mathrm{C}$ \\
\hline ML2 & Manali & $32.25^{\circ} \mathrm{N} 77.18^{\circ} \mathrm{E}$ & 514 & $\mathrm{C}$ \\
\hline ML3 & iválall & $32.24^{\circ} \mathrm{N} 77.19^{\circ} \mathrm{E}$ & 479 & $\mathrm{C}$ \\
\hline ML4 & & $32.25^{\circ} \mathrm{N} 77.19^{\circ} \mathrm{E}$ & 569 & $\mathrm{C}$ \\
\hline
\end{tabular}


Table 1 (continuation)

\begin{tabular}{|c|c|c|c|c|}
\hline Site id & City name & Location & $\begin{array}{c}\text { Average } V s_{30} \\
{[\mathrm{~m} / \mathrm{s}]}\end{array}$ & Soil type \\
\hline MD1 & & $31.72^{\circ} \mathrm{N} 76.93^{\circ} \mathrm{E}$ & 240 & $\mathrm{D}$ \\
\hline MD2 & & $31.71^{\circ} \mathrm{N} 76.94^{\circ} \mathrm{E}$ & 539 & $\mathrm{C}$ \\
\hline MD3 & Mand1* & $31.68^{\circ} \mathrm{N} 76.92^{\circ} \mathrm{E}$ & 352 & $\mathrm{D}$ \\
\hline MD4 & & $31.70^{\circ} \mathrm{N} 76.95^{\circ} \mathrm{E}$ & 406 & $\mathrm{C}$ \\
\hline $\mathrm{NH1}$ & & $30.56^{\circ} \mathrm{N} 77.30^{\circ} \mathrm{E}$ & 486 & $\mathrm{C}$ \\
\hline $\mathrm{NH} 2$ & Nahan* & $30.56^{\circ} \mathrm{N} 77.29^{\circ} \mathrm{E}$ & 407 & $\mathrm{C}$ \\
\hline $\mathrm{NH} 3$ & & $30.57^{\circ} \mathrm{N} 77.30^{\circ} \mathrm{E}$ & 484 & $\mathrm{C}$ \\
\hline NK1 & Nako & $31.89^{\circ} \mathrm{N} 78.63^{\circ} \mathrm{E}$ & 390 & $\mathrm{C}$ \\
\hline RP1 & Reckong & $31.54^{\circ} \mathrm{N} 78.27^{\circ} \mathrm{E}$ & 454 & $\mathrm{C}$ \\
\hline $\mathrm{RP} 2$ & Peo* & $31.54^{\circ} \mathrm{N} 78.27^{\circ} \mathrm{E}$ & 348 & $\mathrm{D}$ \\
\hline RA1 & Rampur & $31.44^{\circ} \mathrm{N} 77.63^{\circ} \mathrm{E}$ & 313 & $\mathrm{D}$ \\
\hline SL1 & & $31.10^{\circ} \mathrm{N} 77.15^{\circ} \mathrm{E}$ & 525 & $\mathrm{C}$ \\
\hline SL2 & & $31.10^{\circ} \mathrm{N} 77.11^{\circ} \mathrm{E}$ & 254 & $\mathrm{D}$ \\
\hline SL3 & & $31.09^{\circ} \mathrm{N} 77.14^{\circ} \mathrm{E}$ & 351 & $\mathrm{D}$ \\
\hline SL4 & & $31.09^{\circ} \mathrm{N} 77.14^{\circ} \mathrm{E}$ & 779 & B \\
\hline SL5 & & $31.09^{\circ} \mathrm{N} 77.15^{\circ} \mathrm{E}$ & 367 & $\mathrm{C}$ \\
\hline SL6 & & $31.11^{\circ} \mathrm{N} 77.16^{\circ} \mathrm{E}$ & 346 & $\mathrm{D}$ \\
\hline SL7 & Shimla* ${ }^{+}$ & $31.12^{\circ} \mathrm{N} 77.18^{\circ} \mathrm{E}$ & 352 & $\mathrm{D}$ \\
\hline SL8 & & $31.08^{\circ} \mathrm{N} 77.17^{\circ} \mathrm{E}$ & 378 & $\mathrm{C}$ \\
\hline SL9 & & $31.10^{\circ} \mathrm{N} 77.17^{\circ} \mathrm{E}$ & 472 & $\mathrm{C}$ \\
\hline SL10 & & $31.08^{\circ} \mathrm{N} 77.17^{\circ} \mathrm{E}$ & 296 & $\mathrm{D}$ \\
\hline SL11 & & $31.08^{\circ} \mathrm{N} 77.18^{\circ} \mathrm{E}$ & 329 & $\mathrm{D}$ \\
\hline SL12 & & $31.09^{\circ} \mathrm{N} 77.21^{\circ} \mathrm{E}$ & 541 & $\mathrm{C}$ \\
\hline SL13 & & $31.12^{\circ} \mathrm{N} 77.22^{\circ} \mathrm{E}$ & 494 & $\mathrm{C}$ \\
\hline SO1 & & $30.92^{\circ} \mathrm{N} 77.09^{\circ} \mathrm{E}$ & 417 & $\mathrm{C}$ \\
\hline $\mathrm{SO} 2$ & & $30.91^{\circ} \mathrm{N} 77.10^{\circ} \mathrm{E}$ & 469 & $\mathrm{C}$ \\
\hline $\mathrm{SO} 3$ & Solan* & $30.90^{\circ} \mathrm{N} 77.09^{\circ} \mathrm{E}$ & 447 & $\mathrm{C}$ \\
\hline $\mathrm{SO} 4$ & & $30.89^{\circ} \mathrm{N} 77.07^{\circ} \mathrm{E}$ & 520 & $\mathrm{C}$ \\
\hline $\mathrm{SO} 5$ & & $30.92^{\circ} \mathrm{N} 77.09^{\circ} \mathrm{E}$ & 452 & $\mathrm{C}$ \\
\hline SU1 & & $31.53^{\circ} \mathrm{N} 76.91^{\circ} \mathrm{E}$ & 379 & $\mathrm{C}$ \\
\hline SU2 & Sundernagar & $31.52^{\circ} \mathrm{N} 76.88^{\circ} \mathrm{E}$ & 317 & $\mathrm{D}$ \\
\hline $\mathrm{T} 1$ & Tabo & $32.09^{\circ} \mathrm{N} 78.38^{\circ} \mathrm{E}$ & 542 & $\mathrm{C}$ \\
\hline U1 & & $31.47^{\circ} \mathrm{N} 76.27^{\circ} \mathrm{E}$ & 204 & $\mathrm{D}$ \\
\hline $\mathrm{U} 2$ & & $31.46^{\circ} \mathrm{N} 76.26^{\circ} \mathrm{E}$ & 266 & $\mathrm{D}$ \\
\hline U3 & Una* & $31.48^{\circ} \mathrm{N} 76.27^{\circ} \mathrm{E}$ & 183 & $\mathrm{D}$ \\
\hline U4 & & $31.47^{\circ} \mathrm{N} 76.28^{\circ} \mathrm{E}$ & 270 & $\mathrm{D}$ \\
\hline U5 & & $31.52^{\circ} \mathrm{N} 76.29^{\circ} \mathrm{E}$ & 237 & $\mathrm{D}$ \\
\hline
\end{tabular}

Explanations: ${ }^{+}-$capital, ${ }^{*}-$ district headquarters. 
layers is obtained by comparing with theoretical dispersion curves iteratively in a least square sense. Thus, a 1D shear wave velocity profile of the middle of the receiver spread is obtained from each shot gather, as shown in Fig. 1d.

The MASW tests were performed at 73 sites located in 22 important cities, including all the 12 district headquarters, of Himachal Pradesh. The tests were performed in open grounds located within the city limits and proximal to very important structures such as hospitals, administrative buildings, bridges, heliports, schools, etc. Due to the high sensitivity of the geophones, these tests were performed at minimum traffic noise level. These tests resulted in a collection of 73 one-dimensional $V_{S_{30}}$ profiles. The test sites were then classified according to the IBC (2009) classification based on the $V s_{30}$ values, which were calculated as

$$
V s_{30}=\frac{30}{\sum_{i=1}^{n}\left(d_{i} / v_{i}\right)},
$$

where $n$ is the number of layers in the top $30 \mathrm{~m}, d_{i}$ and $v_{i}$ are the thickness $[\mathrm{m}]$ and the shear wave velocity $[\mathrm{m} / \mathrm{s}]$ of the $i$ th layer, respectively. The shear wave velocity profiles of $\mathrm{C}$ and D type sites are shown in Fig. 2. The

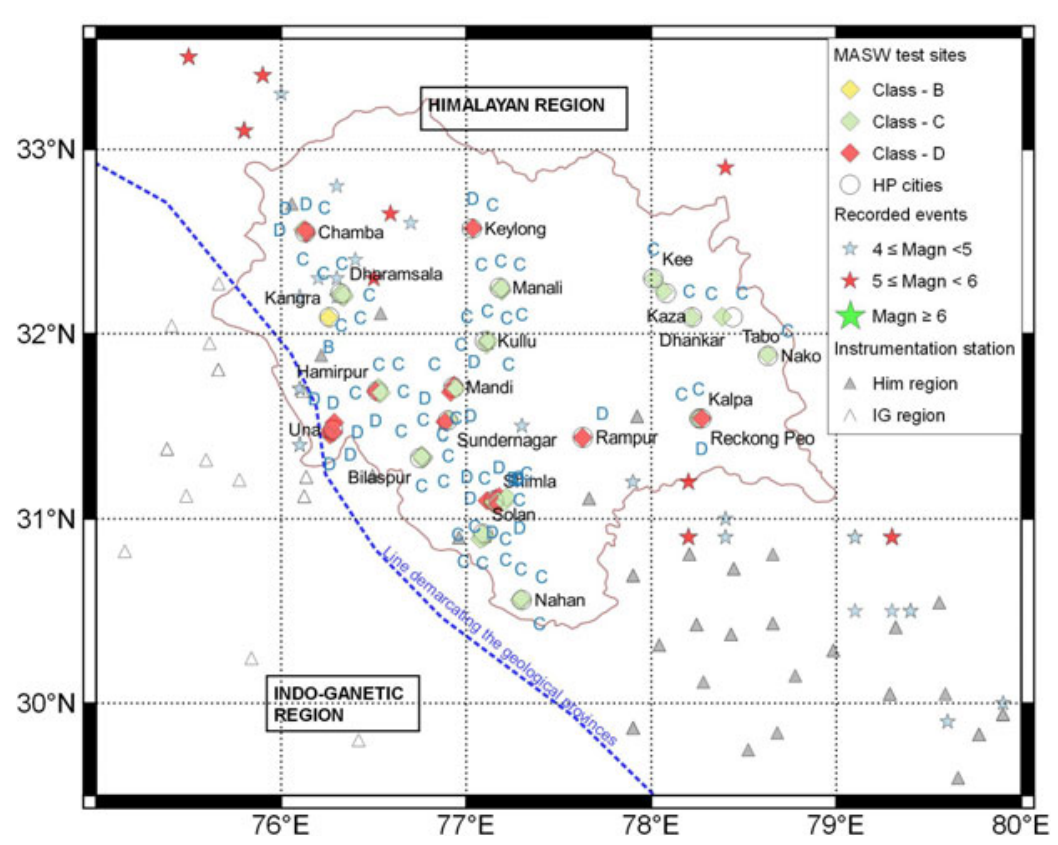

Fig. 3. Location map of the MASW test sites shown along with the site classification based on $V s_{30}$ values. Also are shown the epicentral location of the recorded events used for GMPE validation along with the locations of the instrumentation stations. 
geographic location of the test sites along with the measured $V_{S_{30}}$ values and the site classification as per IBC (2009) are listed in Table 1.

It can be seen from Table 1 that 50 sites were of class C $\left(360 \mathrm{~m} / \mathrm{s}<V s_{30}\right.$ $\leq 760 \mathrm{~m} / \mathrm{s}), 21$ sites were of class D $\left(180 \mathrm{~m} / \mathrm{s}<V_{s_{30}} \leq 360 \mathrm{~m} / \mathrm{s}\right)$, and only 2 sites were of class B $\left(760 \mathrm{~m} / \mathrm{s}<V s_{30} \leq 1500 \mathrm{~m} / \mathrm{s}\right)$. The spatial distribution of the site classes is indicated in Fig. 3. It can be observed that the test sites inthe Indo-Gangetic region are mainly class D sites whereas the shear wave velocities increase in the higher altitude Himalayan regions where the test sites were mainly of class C. Since the major part of the study area falls under either site class $\mathrm{C}$ or $\mathrm{D}$, the existing hazard maps of this region, which are available only for class A sites, cannot be used directly without considering the local site effects. Hence, the site response function have been estimated using these shear wave velocity profiles and are used for developing ground motion relations specific to the class $\mathrm{C}$ and $\mathrm{D}$ site conditions found in this region.

\section{GROUND MOTION RELATIONS}

The reliability of the estimation of seismic hazard at a site depends on how well the uncertainties associated with the source to site path are considered while estimating the ground motion level at the site. These uncertainties associated with the medium characteristics are handled through ground motion relations, which describe the average or other moments of the random hazard parameter (namely, median peak ground acceleration) in terms of magnitude and distance. In this study, the regional properties such as lithographic structure, quality factor (damping); source parameters such as dip angle, focal depth, etc., and soil amplification effects are taken into consideration while developing GMPEs specific to this region. In order to develop these relations, an extensive database of ground motion measures (PGA and $\mathrm{Sa}(\mathrm{T})$ values in this case) for different combinations of magnitude, distance, site conditions, source mechanism, etc., is required. However, the instrumental database for Himalayan and Indo-Gangetic region is sparse (shown in Fig. 4) and is insufficient to derive regional attenuation relationships. Hence, the ground motion relations for such regions have to be based on simulated ground motions, instead of a few past recordings. Stochastic seismological model originally proposed by Boore (1983) is a viable alternative and has been used worldwide for deriving attenuation relationships in regions lacking strong motion data (Atkinson and Boore 1995, Hwang and Huo 1997, Toro et al. 1997). The methodology of generating the synthetic ground motion database incorporating the local site effects, using the shear wave velocity profiles developed in the previous section, and developing regional sitespecific ground motion relations for the study are discussed below. 

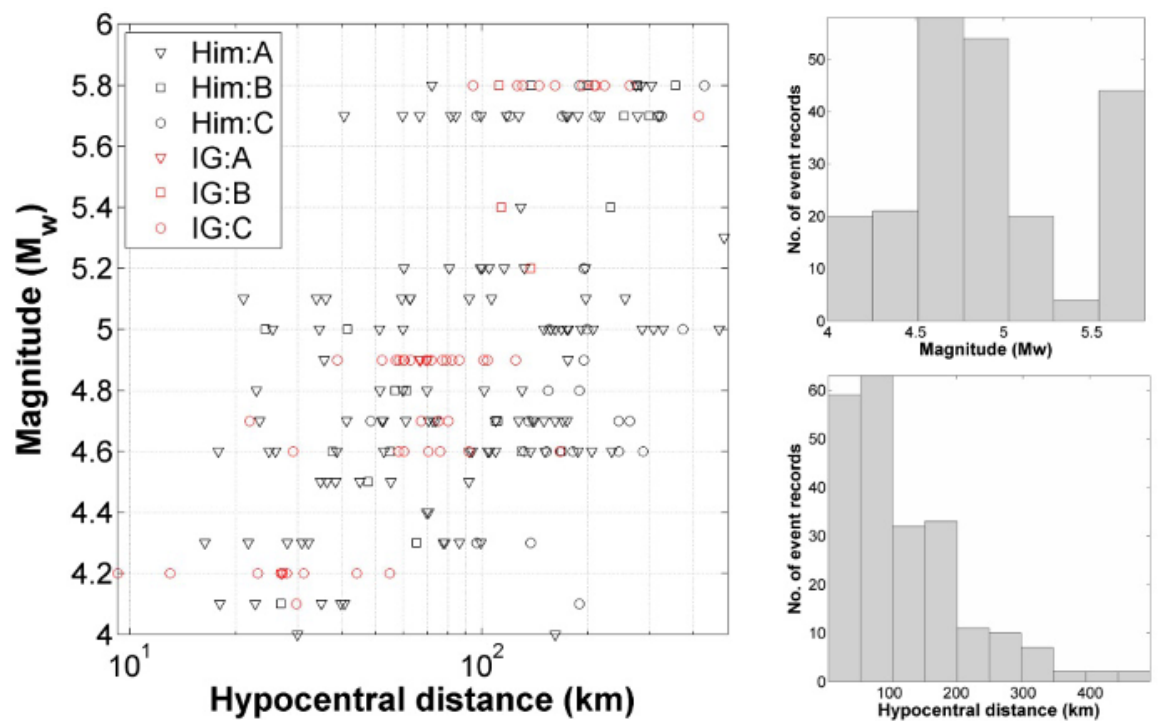

Fig. 4. Distribution of ground motion record based on magnitude, distance, geology, and site class ("Him" refers to Himalayan region and "IG" refers to Indo-Gangetic region).

\subsection{Stochastic seismological model}

In this study, the synthetic ground motion spectra specific to the study region are generated using a finite source model of Motazedian and Atkinson (2005), which extends the point source model of Boore (1983), with the controlling parameters selected based on regional characteristics. These input parameters, namely quality factor, focal depth, and stress drop vary from region to region, depending on the seismo-tectonic setup and geology. The Indian subcontinent is broadly divided into seven geological regions in NDMA (2011) with differing quality factors to estimate ground motions. Among these seven regions, Himalaya and Indo-Gangetic plains control the hazard at Himachal Pradesh whose important regional parameters are listed in Table 2. These regional parameters have been used in the stochastic seismological model, which will be discussed further here.

In this method, a grid of point sources, each of which denotes a sub-fault, represents a rectangular fault plane. The Fourier amplitude spectrum of ground motion $A(r, f)$ due to the $j$ th subfault at a site is derived from the point source seismological model, expressed as

$$
A_{j}(r, f)=C \cdot H_{j} \cdot S_{j}(f) \cdot F(f) \cdot D(r, f) \cdot P(f),
$$

where $C$ is a scaling factor, $S_{j}(f)$ is the source spectral function, $D(r, f)$ is the diminution function characterizing the quality of the region, $P(f)$ is a filter 
Table 2

Uncertainties in earthquake model parameters

\begin{tabular}{|l|c|c|c|c|}
\hline \multicolumn{1}{|c|}{ Region } & $\begin{array}{c}\text { Stress drop } \\
\Delta \sigma[\text { bars }]\end{array}$ & $\begin{array}{c}\text { Dip } \\
{\left[{ }^{\circ}\right]}\end{array}$ & $\begin{array}{c}\text { Focal depth } \\
{[\mathrm{km}]}\end{array}$ & Reference \\
\hline Himalaya & $50-200$ & $2^{\circ}-30^{\circ}$ & $5-40$ & Kayal (2008) \\
Indo-Gangetic Plain & $50-200$ & $10^{\circ}-80^{\circ}$ & $5-40$ & Kayal (2008) \\
\hline
\end{tabular}

function, $F(f)$ is the site dependent function that modifies the bed rock motion in the vertical direction, and $H_{j}$ is a scaling factor used for conserving the energy of high-frequency spectral level of sub-faults. Modification between bedrock and A type site is a linear problem in one-dimension and hence for such sites, amplification function $F(f)$ in Eq. 2 can be directly found by the quarter-wavelength method of Boore and Joyner (1997).

In this study, the principal source model $S_{j}(f)$ for a $j$ th source, developed by Brune (1970), is taken as a function of the seismic moment $\left(M_{0 j}\right)$ and the corner frequency $f_{0 j}$ is given below as follows:

$$
S_{j}(f)=(2 \pi \mathrm{f})^{2} \frac{M_{0 j}}{\left[1+\left(f / f_{0 j}\right)^{2}\right]} .
$$

The three important seismic source parameters, namely $M_{0 j}, f_{0 j}$, and the stress drop $(\Delta \sigma)$, are related through

$$
f_{0 j}=4.9 \times 10^{6}\left(N_{R j}\right)^{-1 / 3} N^{1 / 3} V_{s}\left(\frac{\Delta \sigma}{M_{0 j}}\right)^{1 / 3},
$$

where $V_{s}$ stands for the shear wave velocity in the source region, corresponding to bedrock conditions, and $N_{R j}$ is the cumulative number of ruptured subfaults by the time rupture reaches the $j$ th subfault. The shear wave velocity and density at the focal depth are fixed at $3.6 \mathrm{~km} / \mathrm{s}$ and $2900 \mathrm{~kg} / \mathrm{m}^{3}$, respectively, for both the active regions corresponding to compressed hard granite (Singh et al. 1999). The regional velocity model used for both the active regions is the one reported by NDMA (2011). The spatial modifying function $D(f)$ is given by

$$
D(r, f)=G \exp \left(\frac{-\pi f r}{V_{s} Q(f)}\right),
$$

where $G$ is the geometric attenuation factor. The exponential term denotes anelastic attenuation with hypocentral distance $r$ and the quality factor $Q$. The spatial spread of the ground motion depends sensitively on the quality 
factor of the local region. The quality factor for the Himalayan region has been reported as $253 f^{0.8}$ by Singh et al. (2004) after analysing the ground motion from two major earthquakes that occurred in this region, viz., the 1991 Uttarkashi earthquake and the 1999 Chamoli earthquake. Likewise, Mohanty et al. (2009) have reported the quality factor for Indo-Gangetic plain as $142 f^{1.04}$ based on the strong motion data of 55 earthquakes of magnitude 1.5 to 4.2 acquired from Delhi telemetric network. The spatial modifier of Eq. 5 consists of a general geometrical attenuation term $G$ which is taken as (Singh et al. 1999)

$$
G=\left\{\begin{array}{cl}
1 / r & , \text { for } r \leq 100 \\
1 / 10 \sqrt{r}, & \text { for } r>100
\end{array} .\right.
$$

The constant $C$ of Eq. 2 is

$$
C=\frac{\left\langle R_{\theta \varphi}\right\rangle \sqrt{2}}{4 \pi \rho V_{s}^{3}},
$$

where $\rho$ is the material density at the focal depth. The $S$-wave radiation coefficient $\left.\left(<R_{\theta \phi}\right\rangle\right)$ in the above Eq. 7 varies randomly within particular intervals and is taken to be in the interval 0.48-0.64 (Boore and Boatwright 1984). The coefficient $\sqrt{2}$ in the above equation arises as the product of the free surface amplification and partitioning of energy in orthogonal directions. The scaling factor for $j$ th sub-fault, $H_{j}$, based on the squared acceleration spectrum is taken as (Boore 2009)

$$
H_{j}=\sqrt{N} \frac{f_{0}^{2}}{f_{0 j}^{2}},
$$

where $f_{0}$ is the corner frequency at the end of the rupture which can be obtained by substituting $N_{R}(t)=N$ in Eq. 8. The filter function $P_{j}(f)$ is taken as

$$
P_{j}(f)=\frac{\sqrt{N}}{H_{j}} \frac{1+\left(f / f_{0 j}\right)^{2}}{1+\left(f / f_{0}\right)^{2}} .
$$

The moment of $j$ th subfault is computed from the slip distribution as follows

$$
M_{0 j}=\frac{M_{0} D_{j}}{\sum_{j=1}^{N} D_{j}} .
$$

Here, $D_{j}$ is the average final slip acting on the $j$ th subfault and $M_{0}$ is the total seismic moment on the fault. To further account for earthquake rupture, Motazedian and Atkinson (2005) introduced the concept of pulsing area where 
the cumulative number of active subfaults $\left(N_{R j}\right)$ increases with time after the initiation of rupture and becomes constant at some fixed percentage of the total rupture area. This parameter determines the number of active subfaults during the rupture of the $j$ th subfault. As a result, $N_{R j}$ subfaults will be considered for computing the corner frequency $f_{0 j}$ given in Eq. 4 . The above is a general finite source model expressed in the frequency domain, valid for any region if only the various controlling parameters can be selected suitably. In addition to the above parameters, the pulsing percentage area required in the simulation is varied from 25 to $75 \%$.

\subsection{Sample ground motion}

From the above discussion, it is seen that once the stress drop and quality factors for the region are known, then the Fourier amplitude spectrum of ground acceleration for a given magnitude $(M w)$ and hypocentral distance $(r)$ can be expressed within the limitations of a finite source seismological model. An ensemble of accelerograms can be retrieved from Eq. 2 in three steps. First, a Gaussian stationary white noise sample of length equal to the strong motion duration (Boore and Atkinson 1987)

$$
T=\left(1 / f_{c}+0.05 r\right)
$$

is simulated for each subfault. This sample is multiplied by a suitable nonstationary modulating function suggested by Saragoni and Hart (1973). The simulated sample is Fourier transformed into the frequency domain. This Fourier spectrum is normalized by its root mean-square value and multiplied by the seismological source-path-site function $A(f)$ of Eq. 2. The resulting function is transformed back into the time domain to get a sample of the ground motion accelerogram for each subfault. The simulated acceleration time histories for all the sub-faults are summed up with a time delay of $\Delta t_{j}$ that accounts for the rupture propagation, to obtain the final ground acceleration expressed as

$$
a(t)=\sum_{j=1}^{N} a_{j}\left(t+\Delta t_{j}\right) .
$$

This way, a synthetic database of ground motion using the regional properties has been simulated for all the necessary magnitude and distance ranges. The spectral values of acceleration is then computed from response spectra corresponding to $5 \%$ damping.

\subsection{Site amplification function}

In addition to the uncertainties in the magnitudes and epicentral distances, it is also important to consider the variations in the soil profiles for simulating 
the spectral accelerations at the ground surface. It is observed from Table 1 that the test sites in HP can be classified into class C and D. The general approach of finite source seismological model described above can be extended to these two site classes with the help of depth sections sampled from the region with known $V_{S_{30}}$ values. The modification of ground motion between the bedrock and the surface of the class A sites is a linear problem in one dimension. However, in the case of class B, C, and D type profiles, the soil layering, viscoelastic properties, and nonlinear effects are important. Therefore, the modification of ground motion between the class A and the overlying soil can be treated as a one-dimensional nonlinear problem and the site amplification can be directly found by means of a nonlinear site response analysis. The equivalent linear site response analysis method of Idriss and Sun (1992) implemented in the SHAKE91 software has been used in this study. The main assumption in this method is that the response of a soil deposit to an upward propagating shear waves from the underlying rock formation to the overlying soil mass is analysed to obtain the frequency response of the site dependent function $F(f)$. Therefore, the acceleration time histories are first generated for class A rock profiles from the seismological model discussed earlier and are used as the input ground motion at basement for the class $\mathrm{C}$ and $\mathrm{D}$ type profiles. Thus, for a specific site, modification of the bedrock results is possible by considering the dynamic characteristics of the soil strata. The nonlinear behaviour of the soil, characterized in terms of reduction of shear modulus and increase of damping ratio with shear strain, can be accounted by using equivalent linear soil properties. In this study, the standard curves for shear modulus reduction versus shear strain curves and damping ratio versus shear strain curves proposed by Vucetic and Dobry (1991) for different soil types are used. The frequency response function (FRF) defined as the surface response for a rock level sinusoidal motion of unit amplitude is estimated for all the 73 shear wave velocity profiles. These functions for both class $\mathrm{C}$ and $\mathrm{D}$ sites are shown in Fig. 5. Also, it can be seen from Fig. 6 that the $V_{s_{30}}$ values of majority of these sites lie within 330$550 \mathrm{~m} / \mathrm{s}$ range. This can be attributed to the fact that these test sites, essentially located within urban centres in these mountainous regions, had been prepared by slope levelling and land filling for urban uses. Hence, only moderate differences in the site response functions are observed in certain frequency ranges.

Hence, the acceleration time histories in the synthetic database generated for class A rock profiles can be modified to surface ground motions by using the evaluated class $\mathrm{C}$ and $\mathrm{D}$ site response function. These functions shall be used to generate a database of synthetic surface level response spectra as discussed in the following section. 

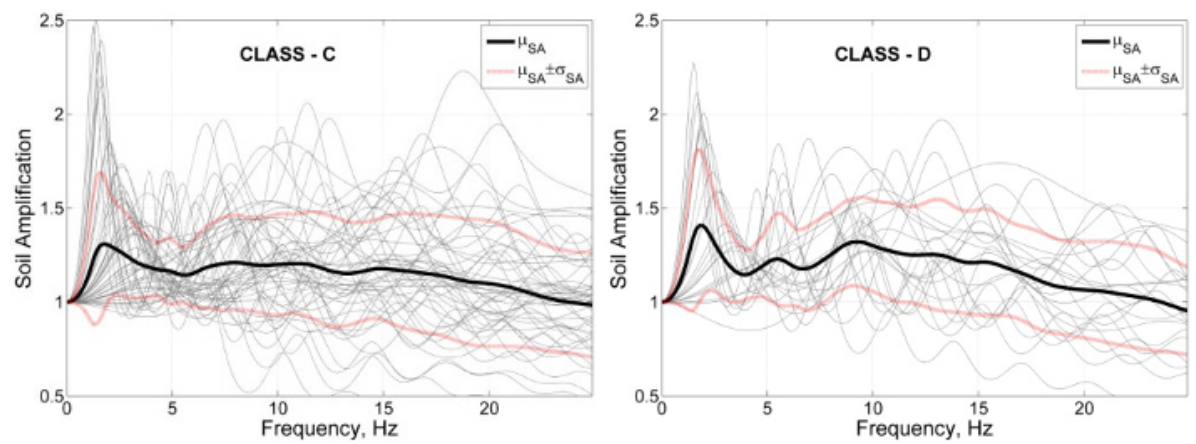

Fig. 5. Mean frequency response function of site amplification for the 50 class $\mathrm{C}$ sites and 21 class D sites.

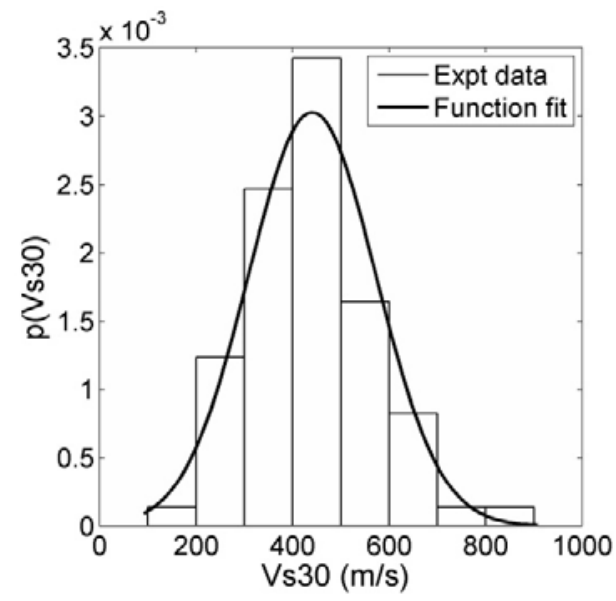

Fig. 6. Distribution of the measured $V s_{30}$ values.

\subsection{Synthetic ground motion database}

In this study, horizontal components of the spectral acceleration values have been simulated for moment magnitude $(M w)$ ranging from 4 to 8.5 in increments of 0.5 units, at 20 values of hypocentral distances ranging from 1 to $500 \mathrm{~km}$. To capture the finiteness of the source, the ground motions are also simulated for eight azimuths ranging from $0^{\circ}$ to $315^{\circ}$ in increments of $45^{\circ}$. Thus, a total number of 160 distance samples are considered for each magnitude. In all, there are 1600 pairs of magnitudes and distances. Since the stress drop, focal depth, dip, radiation coefficient, and pulsing percentage area are random variables, we have included the uncertainty arising out of these parameters also. It can be observed from Table 1 that there are 50 class $\mathrm{C}$ sites and 21 class D sites in HP. The uncertainty associated with the local site amplification has to be included in the ground motion relations. Fifty 
samples of stress drop, focal depth, dip, radiation coefficient, pulsing percentage area, and shear wave velocity profiles are generated. These samples are combined using the Latin Hypercube sampling technique (Iman and Conover 1980) to select fifty random seismic parameters sets for each magnitude value. The acceleration time histories are first simulated for class A site using the amplification function reported in NDMA (2011). The simulated time histories combined with the developed shear wave velocity profiles are used as input to SHAKE91 to obtain the surface level response spectrum. Thus, a database of 80000 PGA and Sa samples corresponding to 1600 simulated earthquake events are generated assuming 5\% damping. This synthetic database is developed separately for both Himalayan and IndoGangetic regions for both class $\mathrm{C}$ and $\mathrm{D}$ type site conditions.

\subsection{Ground motion prediction equations (GMPE)}

The study region comprises both Himalaya and Indo-Gangetic (IG) plain; the differences in the faulting mechanisms in these two regions result in different characteristic ground motions. Therefore, it becomes necessary to develop separate relations for both class $\mathrm{C}$ and $\mathrm{D}$ sites in these two geological regions. Hence, the simulated surface-level response spectra for both class $\mathrm{C}$ and $\mathrm{D}$ sites of both the geological regions are used to develop the ground motion relations. Using the simulated database of 80000 samples of surface level ground motion, the ground motion prediction equation (GMPE) reported by the NDMA (2011) can be updated to predict the surface level hazard measure in the Himachal Pradesh region. The functional form of the GMPE is adopted from NDMA (2011) as

$$
\begin{aligned}
\ln \left(\frac{S_{a}}{g}\right) & =c_{1}+c_{2} M+c_{3} M^{2}+c_{4} r+c_{5} \ln \left(r+c_{6} e^{c_{7} M}\right)+c_{8} \log (r) f_{0}+\ln (\varepsilon) \\
f_{0} & =\max (\ln (r / 100), 0)
\end{aligned}
$$

Here, $S_{a}$ is the spectral acceleration, $M$ is the moment magnitude, and $r$ is the hypocentral distance in $\mathrm{km}$. This form of the attenuation accounts for geometrical spreading, anelastic attenuation and magnitude saturation. Hypocentral distance has been used as the distance measure since reliable estimates of other distance measures that depend on the rupture characteristics are not available for this region. The coefficients $\left(c_{1}, \ldots, c_{8}\right)$ are evaluated from the simulated database of 80000 samples using a two-step stratified regression analysis procedure proposed by Joyner and Boore (1981). These coefficients for the class $\mathrm{C}$ and D sites in both the Himalayan and IG region are reported in Tables 3 to 6 for 28 different time periods. The sufficiency of the functional form of the presented GMPE to represent the simulated data was tested by examining the trend of the residuals. Figure 7 shows the distribu- 
Table 3

Coefficients of the GMPE for class $\mathrm{C}$ sites in the Himalayan region

\begin{tabular}{|c|c|c|c|c|c|c|c|c|c|}
\hline $\begin{array}{c}\text { Period } \\
{[\mathrm{s}]} \\
\end{array}$ & $c_{1}$ & $c_{2}$ & $c_{3}$ & $c_{4}$ & $c_{5}$ & $c_{6}$ & $c_{7}$ & $c_{8}$ & $\sigma(\varepsilon)$ \\
\hline 0 & -4.7738 & 5004 & 0.0204 & -0.0048 & -1.4216 & .0465 & 0.8748 & 0.0912 & 0.3864 \\
\hline 0.01 & -4.7739 & 5004 & -0.0204 & -0.0048 & -1.4216 & 0.0465 & 0.8748 & 0.0912 & 0.3863 \\
\hline 0.015 & -4.3856 & 1.4517 & -0.0166 & -0.0048 & -1.4447 & 0.0526 & 0.8614 & 0.0822 & 0.4077 \\
\hline 0.02 & -3.9633 & 3831 & -0.0117 & -0.0048 & -1.4506 & 0.0512 & 0.8648 & 0.0732 & 0.4246 \\
\hline 0.03 & -3.3644 & 1.2550 & -0.0029 & -0.0050 & -1.4188 & 0.0385 & 0.8975 & & 0.4248 \\
\hline 0.04 & -3.2107 & 1.1993 & 0.0002 & -0.0053 & -1.3663 & 0.0265 & 0.9381 & 0.0721 & 0.4138 \\
\hline 0.05 & -3.1912 & 1.1821 & 0.0007 & -0.0056 & -1.3237 & 0.0189 & 0.9734 & 0.0805 & 0.4050 \\
\hline 0.06 & -3.2716 & 1.1903 & -0.0007 & -0.0057 & -1.2895 & 0.0154 & 0.9926 & 0.0870 & 0.3962 \\
\hline 0.075 & -3.5 & 1.2357 & -0.0046 & -0.00 & -1.2687 & 0.0141 & & & 0.3877 \\
\hline 0.09 & -3.7079 & 1.2796 & -0.0082 & -0.0 & -1.2 & 0.0140 & 9956 & 0.0960 & 836 \\
\hline 0.1 & -3.9358 & 1.3384 & -0.0128 & -0.0056 & -1.2546 & 0.0155 & 0.9808 & 0.0987 & 0.3792 \\
\hline 0.15 & -5.1125 & 1.6079 & -0.0328 & -0.00 & -1.23 & 0.0186 & 0.9500 & 028 & 0.3688 \\
\hline 0.2 & & & -0.0531 & & -1.2201 & & & & \\
\hline 0.3 & -8.5491 & 2.4630 & -0.0947 & -0.0049 & -1.2018 & 0.0419 & 0.8384 & 0.1008 & 0.3623 \\
\hline 0.4 & -10.4802 & 2.9546 & -0.1292 & -0.0046 & -1.1930 & 0.0632 & 0.7866 & 0.0988 & 0.3628 \\
\hline 0.5 & & 3.3690 & -0.1578 & -0.00 & -1.1906 & 0.0800 & & 0.0964 & 0.3609 \\
\hline 0.6 & & & & & -1.17 & & & & 0.3620 \\
\hline 0.7 & -14.8718 & 4.0333 & -0.2024 & -0.0042 & -1.1982 & 0.1174 & 0.7123 & 0.0951 & 0.3591 \\
\hline 0.75 & -15.4146 & 4.1593 & -0.2106 & -0.0041 & -1.2007 & 0.1232 & 0.7060 & 0.0941 & 0.3587 \\
\hline 0.8 & -15.9659 & & -0.2190 & & -1.2118 & & & & 0.3564 \\
\hline 0.9 & & & -0.2348 & -0.0040 & -1.2160 & 0.1491 & & 0.0996 & 0.3539 \\
\hline 1 & -17.5645 & 4.6512 & -0.2416 & -0.0039 & -1.2171 & 0.1562 & 0.6857 & 0.0975 & 0.3519 \\
\hline 1.2 & -19.1139 & & -0.2602 & -0.0038 & -1.2145 & & & 0.0987 & 0.3423 \\
\hline 1.5 & -20.4006 & 5.2107 & -0.2722 & -0.0037 & -1.2349 & 0.1624 & 0.6888 & 0.1004 & 0.3309 \\
\hline 2 & -21.8815 & 5.4498 & -0.2809 & -0.0035 & -1.2588 & 0.1626 & 0.6999 & 0.1000 & 0.3180 \\
\hline 2.5 & -22.7389 & 5.5038 & -0.2787 & -0.0034 & -1.2442 & 0.1228 & 0.7327 & 0.1017 & 0.3128 \\
\hline 3 & -23.2798 & 5.4962 & -0.2700 & -0.0033 & -1.2701 & 0.1139 & 0.7527 & 0.1059 & 0.3086 \\
\hline 4 & -23.5964 & 5.3489 & -0.2483 & -0.0032 & -1.2979 & 0.1001 & 0.7809 & 0.1065 & 0.3093 \\
\hline
\end{tabular}
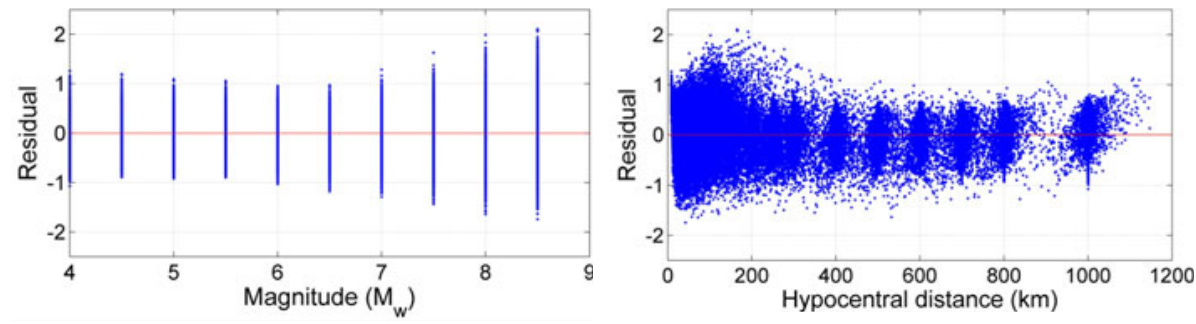

Fig. 7. Residuals $[=\log ($ simulated $P G A)-\log ($ predicted $P G A)]$ plotted as a function of predictor variables $M$ and $R$. 
Table 4

Coefficients of the GMPE for class D sites in the Himalayan region

\begin{tabular}{|c|c|c|c|c|c|c|c|c|c|}
\hline $\begin{array}{c}\text { Period } \\
{[\mathrm{s}]}\end{array}$ & $c_{1}$ & $c_{2}$ & $c_{3}$ & $c_{4}$ & $c_{5}$ & $c_{6}$ & $c_{7}$ & $c_{8}$ & $\sigma(\varepsilon)$ \\
\hline 0 & -4.5304 & .4623 & 0.0175 & 0.0049 & -1.4392 & 0.0365 & .8948 & 0.0985 & 0.3881 \\
\hline 0.01 & -4.5308 & 4624 & 0.0175 & -0.0049 & -1.4392 & 0.0366 & 0.8947 & 0.0985 & 0.3881 \\
\hline 0.015 & -4.1180 & 1.4086 & -0.0134 & -0.0049 & -1.4658 & 0.0388 & 0.8877 & 0.0920 & 0.4027 \\
\hline 0.02 & -3.7021 & 3428 & -0.0087 & -0.00 & -1.4735 & 0.0379 & 0.8899 & & 0.4161 \\
\hline 0.03 & -3.1443 & 1.2262 & -0.0008 & -0.0051 & -1.4423 & 0.0299 & 0.9171 & 0.0759 & 0.4176 \\
\hline 0.04 & -2.9824 & 1.1712 & 0.0023 & -0.0054 & -1.3910 & 0.0216 & 0.9527 & 0.0807 & 0.4097 \\
\hline 0.05 & -2.9733 & 1.1591 & 0.0025 & -0.0056 & -1.3503 & 0.0164 & 0.9806 & 0.0884 & 0.4033 \\
\hline 0.06 & -3.0671 & 1.1712 & 0.0007 & -0.0058 & -1.3091 & 0.0130 & 1.0029 & 0.0934 & 0.3964 \\
\hline 0.075 & -3.2796 & & -0.0029 & -0.00 & -1.2 & 0.0119 & & & 0.3909 \\
\hline 0.09 & -3.47 & 1.25 & -0.0066 & -0.0058 & $-1.2^{\prime}$ & 0.0119 & 1.0068 & 0.1015 & 0.3872 \\
\hline 0.1 & -3.7006 & 1.3144 & -0.0110 & -0.0057 & -1.2695 & 0.0130 & 0.9928 & 0.1034 & 0.3835 \\
\hline 0.15 & -4.9730 & 1.5972 & -0.0319 & -0.00 & -1.2 & 0.0156 & 0.9 & 599 & 0.3750 \\
\hline 0.2 & & & & & & & & & \\
\hline 0.3 & -8.5262 & 2.4675 & -0.0948 & -0.0049 & -1.2106 & 0.0330 & 0.8597 & 0.1025 & 0.3700 \\
\hline 0.4 & -10.4727 & 2.9671 & -0.1300 & -0.0047 & -1.1957 & 0.0471 & 0.8125 & 0.1002 & 0.3713 \\
\hline 0.5 & -12.1248 & 3.3786 & -0.1584 & -0.0044 & -1.1 & 0.0575 & 864 & 964 & 0.3698 \\
\hline 0.6 & -13.8033 & & -0.18 & & -1.17 & & & & 0.3699 \\
\hline 0.7 & -14.8673 & 4.0347 & -0.2024 & -0.0041 & -1.1916 & 0.0844 & 0.7419 & 0.0936 & 0.3668 \\
\hline 0.75 & -15.4015 & 4.1591 & -0.2106 & -0.0041 & -1.1962 & 0.0909 & 0.7333 & 0.0934 & 0.3664 \\
\hline 0.8 & -15.9497 & & -0.2189 & -0.0041 & -1.2086 & & & & 0.3636 \\
\hline 0.9 & -17.0185 & & -0.2338 & -0.0040 & -1.2102 & & & 0.09 & 0.3612 \\
\hline 1 & -17.5410 & 4.6380 & -0.2405 & -0.0039 & -1.2095 & 0.1122 & 0.7166 & 0.0968 & 0.3587 \\
\hline 1.2 & -19.0391 & & -0.2582 & -0.0038 & -1.2133 & & & 0.0986 & 0.3489 \\
\hline 1.5 & -20.2986 & 5.1796 & -0.2697 & -0.0037 & -1.2349 & 0.1217 & 0.7160 & 0.1005 & 0.3380 \\
\hline 2 & -21.7272 & 5.4074 & -0.2774 & -0.0035 & -1.2636 & 0.1270 & 0.7236 & 0.1018 & 0.3251 \\
\hline 2.5 & -22.5444 & 5.4556 & -0.2747 & -0.0034 & -1.2543 & 0.0989 & 0.7538 & 0.1038 & 0.3204 \\
\hline 3 & -23.0657 & 5.4404 & -0.2654 & -0.0033 & -1.2791 & 0.0915 & 0.7739 & 0.1081 & 0.3166 \\
\hline 4 & -23.3445 & 5.2846 & -0.2430 & -0.0032 & -1.3093 & 0.0819 & 0.8013 & 0.1096 & 0.3174 \\
\hline
\end{tabular}

tion of residuals (difference between the logarithm of the simulated and predicted PGA values) with respect to predictor variables. Since no visible trend or bias can be observed, the present functional form has been found to sufficiently capture the simulated data. These developed GMPEs can be used to predict the horizontal component of the acceleration values within the study region for a given $M$ and $R$ value. 
Table 5

Coefficients of the GMPE for class $\mathrm{C}$ sites in the Indo-Gangetic region

\begin{tabular}{|c|c|c|c|c|c|c|c|c|c|}
\hline $\begin{array}{c}\text { Period } \\
{[\mathrm{s}]}\end{array}$ & $c_{1}$ & $c_{2}$ & $c_{3}$ & $c_{4}$ & $c_{5}$ & $c_{6}$ & $c_{7}$ & $c_{8}$ & $\sigma(\varepsilon)$ \\
\hline 0 & -4.3477 & 1.2807 & 0.0087 & -0.0064 & -1.2940 & 0.0084 & 1.0489 & 0.1234 & 0.3930 \\
\hline 0.01 & -4.3478 & 1.2805 & 0.0087 & -0.0064 & -1.2938 & 0.0084 & 1.0491 & 0.1234 & 0.3929 \\
\hline 0.015 & -3.9582 & 1.2157 & -0.0042 & -0.0063 & -1.2957 & 0.0077 & 1.0595 & 0.1224 & .4352 \\
\hline 0.02 & -3.5931 & 1.1596 & 0.0004 & -0.0062 & -1.2917 & 0.0072 & 1.0684 & & 0.4514 \\
\hline 0.03 & -3.1401 & 1.1051 & & -0.0062 & -1.2830 & 0.0071 & & & 0.4289 \\
\hline 0.04 & -3.0207 & 1.1033 & 0.0032 & -0.0062 & -1.2733 & 0.0070 & 1.0722 & 0.1185 & 0.4079 \\
\hline 0.05 & -3.0180 & 1.1225 & 0.0020 & -0.0063 & -1.2642 & 0.0067 & 1.0758 & 0.1186 & 0.3960 \\
\hline 0.06 & -3.1225 & 1.1567 & -0.0007 & -0.0063 & -1.2528 & 0.0067 & 1.0739 & 0.1160 & 0.3869 \\
\hline 0.075 & -3.35 & 1.2057 & -0.0043 & -0.0063 & -1.2427 & 0.0067 & & & 0.3806 \\
\hline 0.09 & -3.55 & 1.2520 & -0.00 & -0.0064 & -1.23 & 0.0071 & 1.06 & & 3772 \\
\hline 0.1 & -3.76 & 1.3094 & -0.0118 & -0.0064 & -1.2395 & 0.0086 & 1.0398 & 0.115 & 0.3749 \\
\hline 0.15 & -4.95 & 1.57 & -0.0311 & -0.0065 & -1.2213 & 0.0108 & 1.0066 & 134 & 0.3709 \\
\hline 0.2 & -6.13 & & & & -1.2076 & & & & \\
\hline 0.3 & -8.4797 & 2.4413 & -0.0928 & -0.0065 & -1.1871 & 0.0239 & 0.8986 & 0.1059 & 0.3748 \\
\hline 0.4 & -10.4117 & 2.9257 & -0.1264 & -0.0066 & -1.1766 & 0.0365 & 0.8467 & 0.1029 & 0.3785 \\
\hline 0.5 & -12.0609 & 3.3261 & -0.1538 & -0.0066 & -1.1689 & 0.0434 & & 997 & 3793 \\
\hline 0.6 & -13.7506 & 3.7191 & & -0.0066 & -1.1520 & & & & 0.3813 \\
\hline 0.7 & -14.7700 & 3.9596 & -0.1960 & -0.0066 & -1.1624 & 0.0567 & 0.7902 & 0.0955 & 0.3791 \\
\hline 0.75 & -15.2966 & 4.0758 & -0.2036 & -0.0066 & -1.1613 & 0.0577 & 0.7866 & 0.0946 & 0.3798 \\
\hline 0.8 & -15.8293 & & & & -1.1700 & & & & 0.3783 \\
\hline 0.9 & -16.8659 & 4.4149 & -0.2247 & -0.0067 & -1.1629 & & & & 0.376 \\
\hline 1 & -17.3530 & 4.5072 & -0.2303 & -0.0066 & -1.1569 & 0.0575 & 0.7889 & 0.0956 & 0.3741 \\
\hline 1.2 & -18.7600 & & & -0.0067 & -1.1497 & & & & 0.3658 \\
\hline 1.5 & -19.9378 & 4.9550 & -0.2532 & -0.0067 & -1.1508 & 0.0392 & 0.8361 & 0.0980 & 0.3554 \\
\hline 2 & -21.2123 & 5.0947 & -0.2551 & -0.0066 & -1.1485 & 0.0248 & 0.8976 & 0.0962 & 0.3431 \\
\hline 2.5 & -21.8921 & 5.0838 & -0.2484 & -0.0066 & -1.1250 & 0.0113 & 0.9888 & 0.0962 & 0.3388 \\
\hline 3 & -22.2566 & 4.9833 & -0.2334 & -0.0066 & -1.1222 & 0.0046 & 1.1077 & 0.0965 & 0.3350 \\
\hline 4 & -22.2759 & 4.6884 & -0.2015 & -0.0066 & -1.1090 & 0.0006 & 1.3616 & 0.0935 & 0.3321 \\
\hline
\end{tabular}

\section{VALIDATION OF THE DEVELOPED GMPES}

The reliability and the limitation of the developed GMPE can be understood by comparing its predictions with that of the recorded data. The event records (within the considered seismogenic zones) are taken from the Indian national strong motion instrumentation network (Mittal et al. 2012) available at the PESMOS database (http://pesmos.in). From the database, the events with magnitude $M \geq 4$ recorded by stations located within HP within a $500 \mathrm{~km}$ region around HP were considered. A total of 221 records with mag- 
Table 6

Coefficients of the GMPE for class D sites in the Indo-Gangetic region

\begin{tabular}{|c|c|c|c|c|c|c|c|c|c|}
\hline $\begin{array}{c}\text { Period } \\
{[\mathrm{s}]}\end{array}$ & $c_{1}$ & $c_{2}$ & $c_{3}$ & $c_{4}$ & $c_{5}$ & $c_{6}$ & $c_{7}$ & $c_{8}$ & $\sigma(\varepsilon)$ \\
\hline 0 & -4.3343 & 2847 & 0.0090 & 0.0064 & -1.2983 & 0.0086 & 1.0439 & 0.1238 & 0.3941 \\
\hline 0.01 & -4.3345 & 1.7285 & 0.0090 & -0.0064 & -1.2982 & 0.0086 & 1.0441 & 0.1238 & 0.3940 \\
\hline 0.015 & -3.9775 & 1.2241 & -0.0047 & -0.0063 & -1.3000 & 0.0081 & 1.0529 & 0.1226 & 0.4275 \\
\hline 0.02 & -3.6236 & 1.1680 & -0.0008 & -0.0063 & -1.2965 & 0.0076 & 1.0612 & 0.1230 & 0.4427 \\
\hline 0.03 & -3.1667 & 1.1100 & 0.0030 & -0.0062 & -1.2878 & 0.0074 & & & 0.4256 \\
\hline 0.04 & -3.0243 & 1.1055 & 0.0031 & -0.0062 & -1.2788 & 0.0073 & 1.0659 & 0.1187 & 0.4080 \\
\hline 0.05 & -3.0117 & 1.1228 & 0.0020 & -0.0063 & -1.2702 & 0.0069 & 1.0706 & 0.1193 & 0.3979 \\
\hline 0.06 & -3.0916 & 1.1569 & -0.0006 & -0.0063 & -1.2569 & 0.0068 & 1.0699 & 0.1164 & 0.3903 \\
\hline 0.075 & -3.28 & 1.2047 & -0.0042 & -0.00 & -1.2 & 0.0068 & & & 0.3849 \\
\hline 0.09 & -3.4831 & 1.2501 & -0.0076 & -0.00 & -1.2402 & 0.0071 & 1.0604 & 0.1155 & 3821 \\
\hline 0.1 & -3.6939 & 1.3068 & -0.0116 & -0.0064 & -1.2408 & 0.0085 & 1.0390 & 0.1149 & 0.3802 \\
\hline 0.15 & -4.9172 & 1.5764 & -0.03 & -0.00 & -1.2254 & 0.0 & 1.0068 & 138 & 0.3769 \\
\hline 0.2 & & & & & & & & & \\
\hline 0.3 & -8.4950 & 2.4461 & -0.0931 & -0.0066 & -1.1901 & 0.0226 & 0.9023 & 0.1066 & 0.3807 \\
\hline 0.4 & -10.4342 & 2.9399 & -0.1275 & -0.0066 & -1.1754 & 0.0343 & 0.8500 & 0.1030 & 0.3845 \\
\hline 0.5 & -12.0682 & 3.3399 & -0.1549 & -0.00 & -1.1 & 0.0406 & 268 & 991 & 0.3852 \\
\hline 0.6 & -13.7375 & & -0.1814 & & & & & & 0.3871 \\
\hline 0.7 & -14.7482 & 3.9608 & -0.1962 & -0.0066 & -1.1602 & 0.0519 & 0.7969 & 0.0953 & 0.3846 \\
\hline 0.75 & -15.2670 & 4.0734 & -0.2035 & -0.0066 & -1.1597 & 0.0528 & 0.7935 & 0.0945 & 0.3852 \\
\hline 0.8 & -15.7935 & & -0.2110 & -0.0066 & & & & & 0.3835 \\
\hline 0.9 & -16.8245 & 4.4071 & -0.2243 & -0.00 & -1.1622 & & 0.7887 & & 0.3809 \\
\hline 1 & -17.3089 & 4.4987 & -0.2298 & -0.0066 & -1.1567 & 0.0533 & 0.7944 & 0.0960 & 0.3789 \\
\hline 1.2 & -18.6974 & & -0.2442 & -0.0067 & -1.1504 & & & 0.0979 & 0.3704 \\
\hline 1.5 & -19.8625 & 4.9382 & -0.2520 & -0.0067 & -1.1526 & 0.0371 & 0.8395 & 0.0985 & 0.3601 \\
\hline 2 & -21.1173 & 5.0736 & -0.2536 & -0.0066 & -1.1519 & 0.0240 & 0.8987 & 0.0973 & 0.3477 \\
\hline 2.5 & -21.7819 & 5.0600 & -0.2467 & -0.0066 & -1.1299 & 0.0112 & 0.9874 & 0.0974 & 0.3432 \\
\hline 3 & -22.1434 & 4.9604 & -0.2319 & -0.0066 & -1.1280 & 0.0048 & 1.0999 & 0.0977 & 0.3393 \\
\hline 4 & -22.1664 & 4.6684 & -0.2002 & -0.0066 & -1.1153 & 0.0007 & 1.3416 & 0.0949 & 0.3362 \\
\hline
\end{tabular}

nitude and hypocentral distance ranging from $M w 4$ to 5.8 and 9.25 to $489 \mathrm{~km}$ that fall within the study region. Of the total records, the numbers of events reported in the Himalayan and IG region were 165 and 56, respectively. It should be noted that the site classifications of the strong motion stations have been reported based on the overall geology of the region and physical description of the near surface materials and are not based on actual in situ characterization (Mittal et al. 2012). In the Himalayan region, recorded data were reported at 117, 20, and 28 numbers of class A, B, and C 
sites. While the numbers of data records reported at class $\mathrm{A}, \mathrm{B}$, and $\mathrm{C}$ sites of the Indo-Gangetic region were 4, 3, and 49. None of the above records were reported at class D sites. The histograms of the magnitude and distance of the recorded data are shown in Fig. 4.

In the absence of proper site characterization and lack of sufficient data for all the site classes, it has been decided to perform the residual analysis by considering all the recorded dataset in both the Himalayan and IG region to be of class $\mathrm{C}$ type. The residuals were estimated as the difference between the spectral values of the recorded ground motion and the predicted values for the same reported magnitude and hypocentral distance using the developed ground motion relations. The mean and standard deviation of the residuals estimated for different spectral values, ranging from 0.01 to $4 \mathrm{~s}$ time period, are plotted in Fig. 8 for the two geological regions. It can be seen that there is a reasonable agreement between the GMPE predictions and the observed data. It can also be observed that the GMPE predicts higher ground motion in time periods below $0.1 \mathrm{~s}$ and lower ground motion in the long pe-

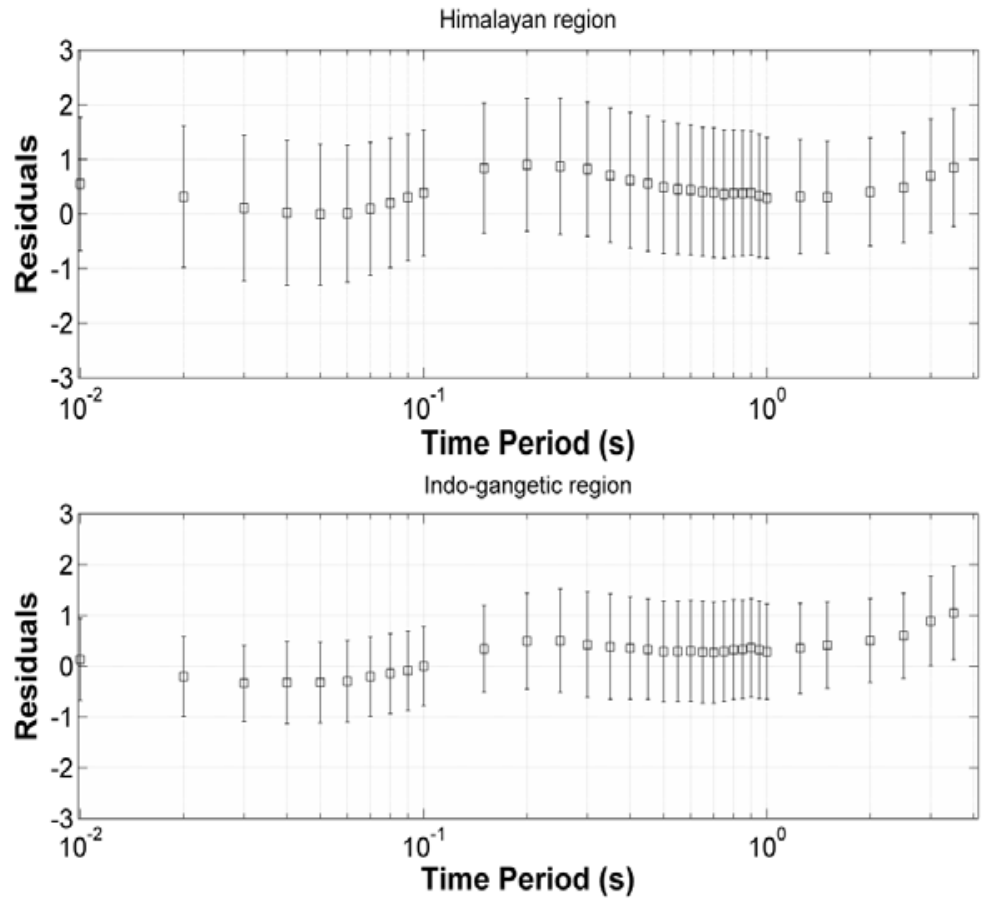

(a)

(b)

Fig. 8. Mean and standard deviation of the residuals depicted as a function of time period for the Himalayan (a) and the Indo-Gangetic region (b). The residuals are computed as the difference between the logarithm of the spectral values of the observed data and that of the predicted data. 

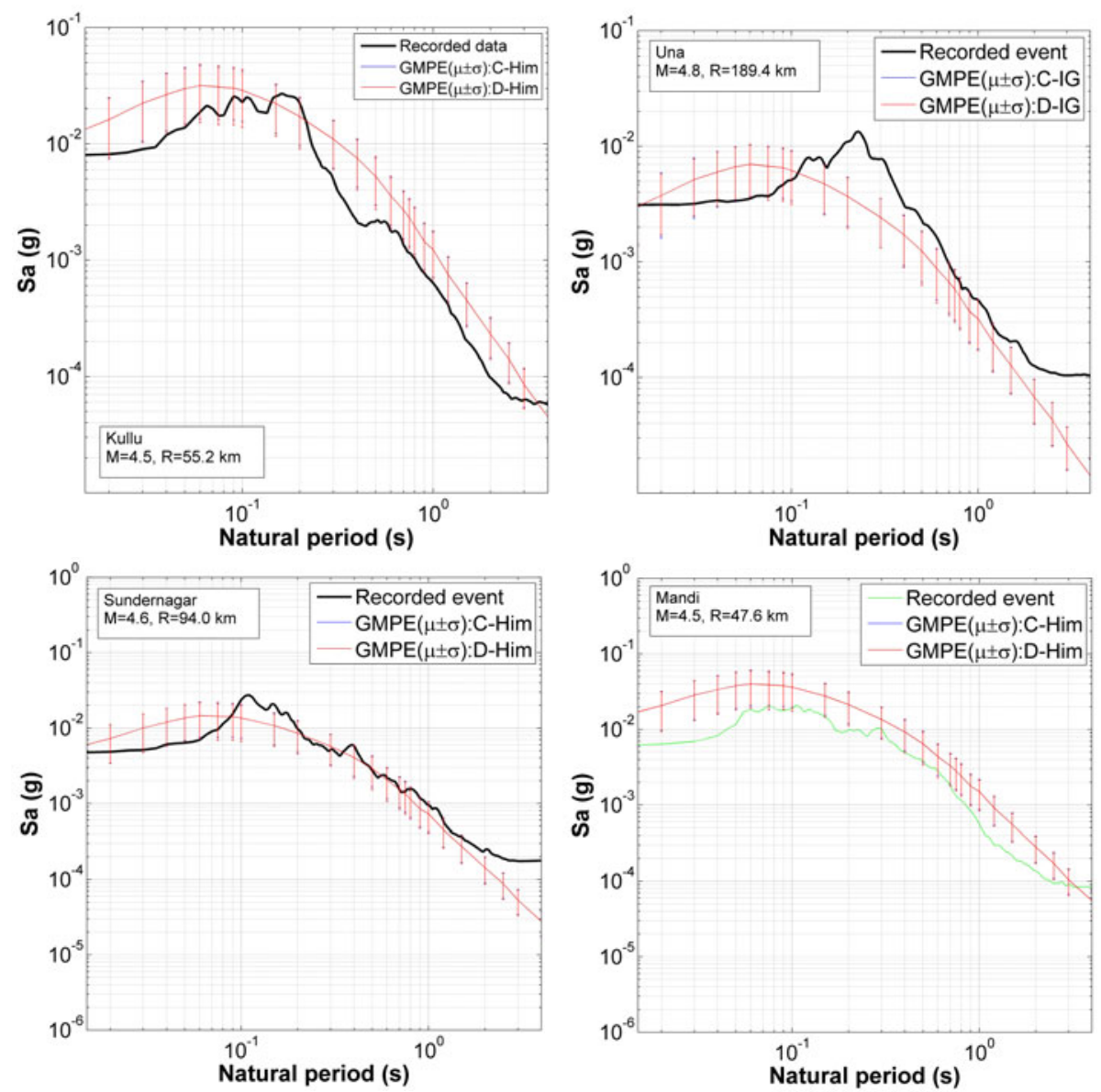

Fig. 9. Comparison of the spectral acceleration (5\% damping) of observed events with the GMPE prediction for some of the test cities.

riod range of above $1.5 \mathrm{~s}$. The comparison between the $5 \%$ damped response spectrum of recorded data at some of the instrumented stations located at 4 test cities and the spectral values predicted by the developed ground motion relations are shown in Fig. 9. It can be seen that there is a good agreement between the predicted and the recorded data with very close PGA predictions at some stations.

In order to highlight the importance of developing site-specific ground motion relations, the prediction of the GMPEs developed in this study are compared with that of the NDMA (2011) developed for class A site conditions as shown in Fig. 10. The comparison made for a moderate as well as a 

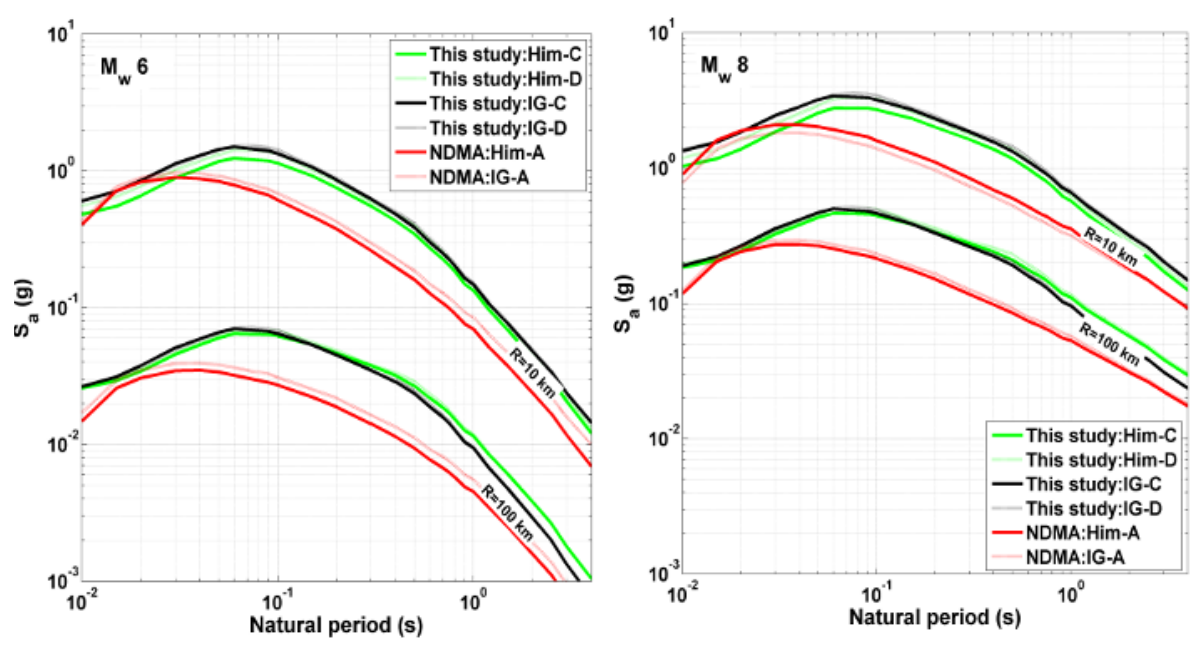

Fig. 10. Comparison of the predicted spectral values of the developed GMPEs (for class $\mathrm{C}$ and D sites in the Himalayan and IG region) with GMPE reported by NDMA (2011; applicable only for class A sites). The spectra are shown for $M_{w}=6,8$ and hypocentral distance of $R=10,100 \mathrm{~km}$.

large magnitude event at near and far distance clearly shows the amplification effects on the spectral acceleration values for class C and D sites.

Furthermore, the importance of developing region-specific ground motion relations is highlighted by comparing the developed GMPEs with other ground motion relations developed based on NGA West-2 database for active shallow crustal regions. The spectral acceleration values, for time periods ranging from 0.01 to $4 \mathrm{~s}$, are predicted for two different magnitude values and hypocentral distances and are shown in Fig. 11. It can be observed from Fig. 11 that the NGA West-2 GMPEs compares well in the time period ranges above $0.2 \mathrm{~s}$ but underestimates the ground motion for periods lower than $0.2 \mathrm{~s}$. However, Fig. 11 shows that the ground motion observed in this region exhibits high frequency content for time period less than $0.2 \mathrm{~s}$ which are predicted reasonably well by the GMPEs presented in this study. Hence, this highlights the need for the regional specific GMPEs such as the ones developed in this study to account for the regional geology, source parameters, and local site effects.

\section{SUMMARY AND CONCLUSIONS}

Despite being a seismically active region, the state of Himachal Pradesh (HP) lacks a robust seismic hazard map based on regional ground motion relation except for the NDMA (2011) relations developed for class A sites. The investigation of the site characteristics, by MASW tests, at 73 locations in 

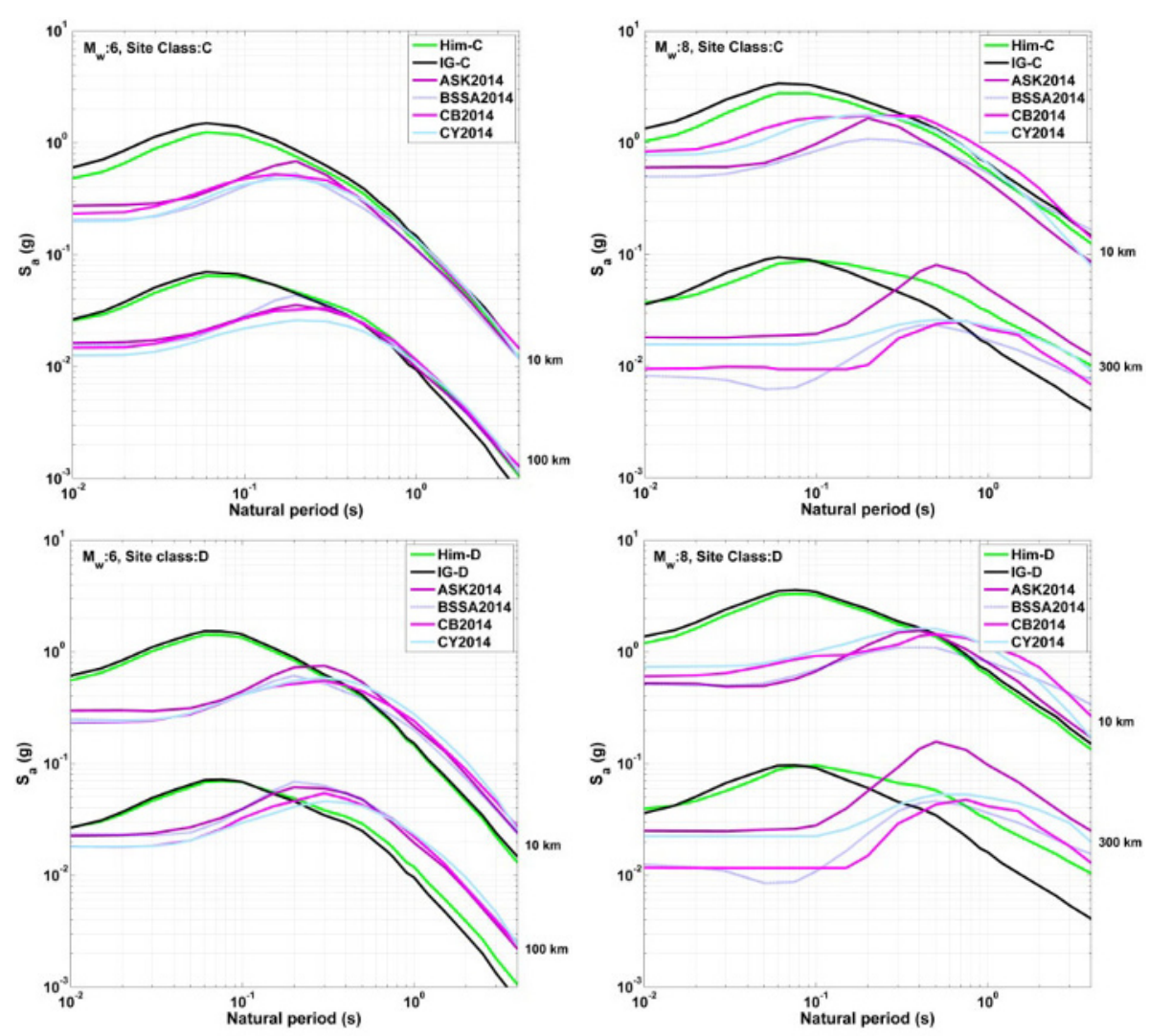

Fig. 11. Comparison of the predicted spectral values of the developed GMPEs with some of the GMPE based on NGA West 2 Data. The spectra are shown for the combination of $M_{w}=6$ and $R=10,100 \mathrm{~km} ; M_{w}=8$ and $R=10,300 \mathrm{~km}$; for class C and D sites. The $V s_{30}$ values for the "NGA West 2" GMPEs were taken as 560 and $270 \mathrm{~m} / \mathrm{s}$ for class C and D, respectively. Note: ASK2014 - Abrahamson et al. (2014), BSSA2014 - Boore et al. (2014), CB2014 - Campbell and Bozorgnia (2014), CY2014 - Chiou and Young (2014).

22 important cities situated across the state of HP indicated that the test sites are mainly of class $\mathrm{C}$ and $\mathrm{D}$ type. This highlights the need to develop regional ground motion relations considering the regional geology and the local site effects.

The development of such ground motion relations require detailed earthquake catalogue for this region. But such a catalogue is not available due to the scarcity of the existing ground motion records. Instead, a simulated database of bedrock ground motions has been generated using the widely adopted stochastic seismological model considering the characteristic features of the source and medium parameters of the two geological regions. The soil 
profiles developed in this study are then used to scale the ground motion simulated for class A sites into the widely prevalent class C and D site responses using an equivalent linear site response analysis. As a result, four synthetic databases of surface ground motions has been generated for both the observed site classes and the two geological regions considering the uncertainties associated with the regional and source parameters.

Using these surface ground motion databases, new ground motion relations for class C and D sites have been developed for the two geological regions. The predictions of these ground motion relations are found to be in reasonable agreement with the observed data. Also, the comparison of the predictions with the existing ground motion relations for class A site highlights the need for site-specific ground motion relations. In addition to that, the comparison with the NGA West-2 ground motion relations highlights the importance of developing regional ground motion relations.

In the present scenario with the limited amount of ground motion data available for this seismically active region, the developed ground motion relations are not only both regional and site-specific but also complements the class A ground motion relations of NDMA (2011). With these ground motion relations, the probable site-specific seismic hazard for this region can be evaluated for practical engineering purposes. Therefore, a detailed probabilistic seismic hazard analysis of this region has been carried out and the results are presented in the companion paper for practical engineering purposes.

Acknowledgments. We thank the support of Dr. G.R. Dodagoudar and Mr. G. Maheshreddy of Indian Institute of Technology Madras while carrying out the MASW tests. The financial support received from the State Government of Himachal Pradesh and the assistance from TARU Leading Edge Pvt. Ltd. are gratefully acknowledged. We thank the reviewers whose suggestions helped to improve the manuscript.

\section{References}

Abrahamson, N.A., W.J. Silva, and R. Kamai (2014), Summary of the ASK14 ground motion relation for active crustal regions, Earthq. Spectra 30, 3, 1025-1055, DOI: 10.1193/070913EQS198M.

Atkinson, G.M., and D.M. Boore (1995), Ground-motion relations for eastern North America, Bull. Seismol. Soc. Am. 85, 1, 17-30. 
Boore, D.M. (1983), Stochastic simulation of high-frequency ground motions based on seismological models of the radiated spectra, Bull. Seismol. Soc. Am. 73, 6A, 1865-1894.

Boore, D.M. (2009), Comparing stochastic point-source and finite-source groundmotion simulations: SMSIM and EXSIM, Bull. Seismol. Soc. Am. 99, 6, 3202-3216, DOI: 10.1785/0120090056.

Boore, D.M., and G.M. Atkinson (1987), Stochastic prediction of ground motion and spectral response parameters at hard-rock sites in eastern North America, Bull. Seismol. Soc. Am. 77, 2, 440-467.

Boore, D.M., and J. Boatwright (1984), Average body-wave radiation coefficients, Bull. Seismol. Soc. Am. 74, 5, 1615-1621.

Boore, D.M., and W.B. Joyner (1997), Site amplifications for generic rock sites, Bull. Seismol. Soc. Am. 87, 2, 327-341.

Boore, D.M., J.P. Stewart, E. Seyhan, and G.M. Atkinson (2014), NGA-West2 equations for predicting PGA, PGV, and 5\% damped PSA for shallow crustal earthquakes, Earthq. Spectra 30, 3, 1057-1085, DOI: 10.1193/ 070113EQS184M.

Brune, J.N. (1970), Tectonic stress and the spectra of seismic shear waves from earthquakes, J. Geophys. Res. 75, 26, 4997-5009, DOI: 10.1029/ JB075i026p04997.

Campbell, K.W., and Y. Bozorgnia (2014), NGA-West2 ground motion model for the average horizontal components of PGA, PGV, and 5\% damped linear acceleration response spectra, Earthq. Spectra 30, 3, 1087-1115, DOI: 10.1193/062913EQS175M.

Chiou, B.S.-J., and R.R. Youngs (2014), Update of the Chiou and Youngs NGA model for the average horizontal component of peak ground motion and response spectra, Earthq. Spectra 30, 3, 1117-1153, DOI: 10.1193/ 072813EQS219M.

Hwang, H., and J.-R. Huo (1997), Attenuation relations of ground motion for rock and soil sites in eastern United States, Soil Dyn. Earthq. Eng. 16, 6, 363372, DOI: 10.1016/S0267-7261(97)00016-X.

IBC (2009), 2009 International Building Code, International Code Council, Inc., Country Club Hills, USA.

Idriss, I.M., and J.I. Sun (1992), SHAKE91: A computer program for conducting equivalent linear seismic response analyses of horizontally layered soil deposits. User's guide, Center for Geotechnical Modeling, Department of Civil and Environmental Engineering, Univ. of California, Davis, USA.

Iman, R.L., and W.J. Conover (1980), Small sample sensitivity analysis techniques for computer models, with an application to risk assessment, Commun. Stat. Theor. Meth. 9, 17, 1749-1842, DOI: 10.1080/03610928008827996.

IS:1893 (2002), Indian standard, Criteria for earthquake resistant design of structures: Part 1, 5th rev., Bureau of Indian Standards, New Delhi, India. 
Joyner, W.B., and D.M. Boore (1981), Peak horizontal acceleration and velocity from strong-motion records including records from the 1979 Imperial Valley, California, earthquake, Bull. Seismol. Soc. Am. 71, 6, 2011-2038.

Kayal, J.R. (2008), Microearthquake Seismology and Seismotectonics of South Asia, Springer, Dordrecht, Capital Publ. Co., New Delhi.

Mittal, H., A. Kumar, and R. Ramhmachhuani (2012), Indian national strong motion instrumentation network and site characterization of its stations, Int. J. Geosci. 3, 6A, 1151-1167, DOI: 10.4236/ijg.2012.326117.

Mohanty, W.K., R. Prakash, G. Suresh, A.K. Shukla, M.Y. Walling, and J.P. Srivastava (2009), Estimation of coda wave attenuation for the national capital region, Delhi, India using local earthquakes, Pure Appl. Geophys. 166, 3, 429-449, DOI: 10.1007/s00024-009-0448-7.

Motazedian, D., and G.M. Atkinson (2005), Stochastic finite-fault modeling based on a dynamic corner frequency, Bull. Seismol. Soc. Am. 95, 3, 995-1010, DOI: $10.1785 / 0120030207$.

Muthuganeisan, P., and S.T.G. Raghukanth (2016), Site-specific probabilistic seismic hazard map of Himachal Pradesh, India. Part II. Hazard estimation, Acta Geophys., DOI: 10.1515/acgeo-2016-0011.

NDMA (2011), Development of probabilistic seismic hazard map of India, Technical Report, Working Committee of Experts (WCE), National Disaster Management Authority (NDMA), New Delhi, India.

Park, C.B., R.D. Miller, and J. Xia (1999), Multichannel analysis of surface waves, Geophysics 64, 3, 800-808, DOI: 10.1190/1.1444590.

Saragoni, G.R., and G.C. Hart (1973), Simulation of artificial earthquakes, Earthq. Eng. Struct. Dyn. 2, 3, 249-267, DOI: 10.1002/eqe.4290020305.

Singh, S.K., R.S. Dattatrayam, N.M. Shapiro, P. Mandal, J.F. Pacheco, and R.K. Midha (1999), Crustal and upper mantle structure of Peninsular India and source parameters of the 21 May 1997, Jabalpur earthquake $(\mathrm{Mw}=5.8)$ : Results from a new regional broadband network, Bull. Seismol. Soc. Am. 89, 6, 1631-1641.

Singh, S.K., D. García, J.F. Pacheco, R. Valenzuela, B.K. Bansal, and R.S. Dattatrayam (2004), Q of the Indian shield, Bull. Seismol. Soc. Am. 94, 4, 15641570, DOI: $10.1785 / 012003214$.

Toro, G.R., N.A. Abrahamson, and J.F. Schneider (1997), Models of strong ground motions from earthquakes in central and eastern North America: best estimates and uncertainties, Seismol. Res. Lett. 68, 1, 41-57, DOI: 10.1785/ gssrl.68.1.41.

Vucetic, M., and R. Dobry (1991), Effect of soil plasticity on cyclic response, J. Geotech. Eng. ASCE 117, 1, 89-107, DOI: 10.1061/(ASCE)0733-9410 (1991)117:1(89).

Received 12 September 2014

Received in revised form 27 March 2015

Accepted 10 April 2015 